\title{
Birding in Bermuda
}

\section{by Ronald M. Bremner, Saskatoon}

Awaken every morning to the several songs of the Cardinal, see Eastern Bluebirds and Catbirds frequently throughout the mild March days, enjoy the calls and colours of the Kiskadee Flycatcher, fancy the flutter of the dainty diminutive Ground Dove-these may sound like the exaggerations of a tourist poster directed to bird-lovers, but all were commonplace evenits during a memorable ten-day vacation which was especially enjoyable after six months of Saskatchewan winter.

Apart from the plethora of ubiquitous House Sparrows which will make any tourist feel immediately at home, the four species just mentioned are the commonest birds in Bermuda. I recorded many others, both familiar and new, a grand total of 28 species-12 not found on the Saskatchewan check-list, nine additions to my own life-list. However, the Bermuda bird most renowned among ornithologists is the island's distinctive petrel, known as the Cahow, and this naturally became the goal of a birder's quest.

All the birds of Bermuda are listed in the standard bird guides, but printed guides are poor substitutes for the personal guidance of a colleague, and so the greatest good fortune of my trip was the discovery of David Wingate-a quiet, enthusiastic, hard-working young man, a native Bermudian who converted his boyhood hobby into his profes sion by graduating in the Cornell course in zoology and returning to his home to become the first and only competent ornithologist on those 22 square miles of volcanic and coral ocean island. The Check List and Guide to the Birds, Mammals, Reptiles and Amphibians of Bermuda which first went on sale (for \$1) during March of this year is attributed to a committee of the Bermuda Audubon Society but is in effect the first publication of its editor David L. Wingate. He has also been chiefly responsible for the magnificent measures now being effectively directed towards the con- servation of Bermuda's natural resources.

The avifauna of Bermuda resembles that of the Carolina coast, rather than the Caribbean, tropical or European regions, and thus much information concerning our native birds, especially in migration, could be learned from this ideal station well out in the Atlantic Ocean. It is thus unfortunate that Bermuda has been so neglected by American ornithologists, even to the point of refusing contributions offered to the Audubon Field Notes. At present birds are well represented in Bermuda mainly as transient migrants or accidental visitors, but the careful and frequent observations by David Wingate over the years have demonstraited that many species once considered rare occur frequently or regularly. The Bermuda Check List lists 284 species, but only 23 of these are nesters. The paucity of breeding passerines is, of course, characteristic of small isolated islands. In Bermuda all nesting land birds are resident throughout the year.

Bermuda was once famed for forests of Bermuda cedar, but these trees are now but skeletons, having been virtually destroyed by a scale insect during the past 15 years. This sudden change in flora has had several effects upon the island's avifauna. The White-Eyed Vireo, once abundant and known to all natives as "Chick - of - the - village," . has greatly diminished; I saw just one during a ten-day search. The Eastern Bluebird has been able to utilize the dead trees as nesting sites and with the increased breeding facilities so provided has actually made a comeback in recent years, in spite of the House Sparrow. The Bermuda Audubon Society has arranged for preservation of some stands of dead trees for nesting birds. However, within the past two years the Starling has posed a new and greater threat to the Bluebird. Although the Starling has been a regular visitor throughout the twentielth century, remarkably it did not establish residence until 1954. Already the 
Bluebirds are imperiled by competition from the rapidly increasing Starlings.

The Kiskadee Flycatcher is an attractive and noisy tropical bird, the large head and beak of which immediately suggest a relationship to the Kingfisher. It was delikerately introduced from Trinidad in 1956, became well established and breeds irregularly throughout the summer months. Its advent can be indirectly attributed to the scourge which has killed Bermuda's cedar forests. Further insects were introduced as parasites upon the cedar scale, but when these new guests became a menace, certain lizards were brought in as a further control. These lizards have literally overrun the island, can be seen at any time on walls and fences and trees and shrubs. Then someone recalled that in the tropics the Kiskadees prey upon the lizards; ergo Bermuda should have Kiskadees to reduce the lizards. The lizards are still as abundant as ever since the the Kiskadees much prefer the bountiful and tasty bananas to furtive darting lizards. What a sad commentary on man's efforts to adjust the forces of nature. At the time, the professionals were advised against the introduction of the Kiskadee by a mere youth, who has since proven himself to be a truly informed scientist-David Wingate.

Bermuda's oceanic birds-elusive creatures, often nocturnal, help to fill a gap in man's knowledge of the natural world. Most dramatic and best known is the "long-tail," the Yellow-billed Tropic Bird which has appeared on the country's postage stamps. It is estimated that between 3000 and 4000 of these birds still breed in crevices on the rocky coast, but these are increasingly menaced by the stray dogs which roam the islands and are really wild. The Longtails are evident from March to September, but for the other half of the year they remain far out in the ocean. They can be seen from shore just from dawn to mid-day; it is almost possible to set one's watch for twelve noon coincident with the departure of the birds for the remote seas out of sight of land.

The other two pelagic birds which breed in Bermuda are the closely related Audubon's Shearwater and Cahow. Both are equally rare for Bermuda, but whereas the fcrmer is found elsewhere in the world, the latter is a unique and isolated species whose total number is probably less than that of the Whooping Crane. As is customary with these exotic creatures, only one egg is laid in any breeding season. For the Shearwater the incubation time is 52 days. Each parent takes a turn at incubating for ten-day periods, and thus remains secluded and without food during a week and a half. This year just three. Shearwater nests are known in Bermuda.

By far the most famous of the surviving sea-birds is the Cahow. Before 1600 it bred in hundreds of thousands, but pigs (released by Spaniards, the first humans on the island) destroyed the majority of birds on the mainland, and the early settlers during the plague of rats between 1614 and 1620 slaughtered nearly all the remainder for food. The bird was presumed extinct for over 300 years, but in 1951 the breeding grounds were located on the most remote and inaccessible of Bermuda's off-shore lava islands. There are this year only nine nests distributed among three small islands, and the breeding population is lower than in other years of the past decade.

The only Cahow I observed was a downy nestling, and the single egg taken from an abandoned nest. To see an adult Cahow, I would have had to spend a night on the barren wind-swept rocks which are so jagged that David Wingate frequently destroys one or two pairs of shoes a month making his daily visits to the breeding grounds. Unfortunately the larger and laterbreeding Tropic Birds preys upon the nests of the Cahow, evicting the helpless petrel nestling in order to lay its own eggs. David Wingate is devising means to protect the Cahow nests, but these and other deitails about this piquant petrel must wait his own article to be published in Canadian Audubon, the periodical of the national organization with which the S.N.H.S. is affiliated and a journal to which all should be subscribers. 